\title{
IPTEK MARIKULTUR BAGI KELOMPOK PEMBUDIDAYA IKAN DESA MOTANDOI SELATAN KECAMATAN PINOLOSIAN TIMUR KABUPATEN BOLAANG MONGONDOW SELATAN
}

(Science and Technology of Marine Aquaculture for Group of Fisheries South Motandoi Village, East Pinolosian District, South Bolaang Mongondow Regency)

\section{Carolus P. Paruntu ${ }^{1 *}$, Suria Darwisito ${ }^{1}$, Antonius P. Rumengan ${ }^{1}$, Hengky J. Sinjal ${ }^{1}$, Billy Wagey ${ }^{1}$ dan Johan Tumiwa ${ }^{2}$}

\author{
${ }^{1)}$ Fakultas Perikanan dan IImu Kelautan Universitas Sam Ratulangi Manado, 95115 \\ ${ }^{2)}$ Fakultas Ekonomi dan Bisnis Universitas Sam Ratulangi Manado, 95115 \\ ${ }^{*}$ Corresponding author: carolusparuntu@yahoo.com
}

\begin{abstract}
The purpose of the community partnership program is to increase the capacity of independent and sustainable marine fish farmers groups. Specific targets are 1) Increasing the quantity and quality of fish products from marine aquaculture in floating net cages, and 2) Enhancing partners' understanding and skills in terms of effective and efficient marine fish aquaculture technology in floating net cages. The main problems recorded, namely: 1) lack of knowledge of marine fish aquaculture technology in floating net cage; 2) fish harvest time that requires a long time, and 3) poor financial management. To overcome these problems, an approach is carried out through direct education and training, mentoring, and management of fisheries business management in the field to partners. After that, each trainee in the partner group is given the opportunity until they can do it themselves. The target that will be achieved at the end of this education and training is that all group members and their families have knowledge of: 1) superior marine fish polyculture technology in floating net cage and 2) good financial management.
\end{abstract}

Keywords: Fish cultivator group, floating net cage, South Motandoi village, financial management, marine fish polyculture technology

Tujuan program kemitraan masyarakat (PKM) adalah meningkatkan kapasitas kelompok pembudidaya ikan laut yang mandiri dan berkelanjutan. Target khusus adalah 1) peningkatan kuantitas dan kualitas produk ikan hasil budidaya laut dalam karamba jaring apung, dan 2) peningkatan pemahaman dan ketrampilan mitra dalam hal teknologi budidaya ikan laut dalam karamba jaring apung yang efektif dan efisien. Permasalahan utama yang terekam, yaitu: 1) kurang pengetahuan tentang teknologi budidaya ikan laut dalam karamba jaring apung $(\mathrm{KJA})$; 2) waktu panen ikan yang membutuhkan waktu yang lama, serta 3) pengelolaan keuangan yang kurang baik. Untuk mengatasi masalah tersebut dilakukan pendekatan melalui penyuluhan dan pelatihan, pendampingan, dan pendidikan manajemen usaha perikanan secara langsung di lapangan kepada mitra. Setelah itu, setiap peserta pelatihan dalam kelompok mitra tersebut diberikan kesempatan sampai mereka bisa melakukannya sendiri. Target akhir yang dicapai dalam PKM ini adalah semua anggota kelompok maupun keluarganya mempunyai pengetahuan tentang: 1) teknologi polikultur budidaya ikan laut dalam karamba jaring apung yang unggul, dan 2) manajemen keuangan yang baik.

Kata-kata kunci: Kelompok pembudidaya ikan, karamba jaring apung, Desa Motandoi Selatan, manajemen keuangan, teknologi polikultur ikan laut

Article History:

Received Oktober 6, 2019

Accepted: Oktober 10, 2019

Published: Oktober 18, 2019 


\section{PENDAHULUAN}

\section{Analisis Situasi}

\section{Aspek lokasi}

Desa Motandoi Selatan adalah salah satu desa defenitif di wilayah Kecamatan Pinolosian Timur, Kabupaten Bolaang Mongondow Selatan, Provinsi Sulawesi Utara. Secara geografis desa ini berada di pesisir pantai serta daratan yang dikelilingi gunung dan perbukitan, dengan luas wilayah $\pm 450 \mathrm{~km}^{2}$. Secara umum Desa
Motandoi Selatan berada pada ketinggian \pm $3 \mathrm{~m}$ di atas permukan laut. Dari segi geografis, desa ini adalah desa pesisir yang perairannya merupakan bagian dari perairan Teluk Tomini (Gambar 1). Mitra berdomisili di desa ini di bagian pesisir pantai, Jaga 1. Mitra memiliki usaha budidaya laut yaitu pemeliharaan ikan laut, seperti ikan kerapu, beronang, kuwe, dan udang dalam karamba jaring apung (pemeliharan satu jenis ikan dalam KJA) (Anonimous, 2010).

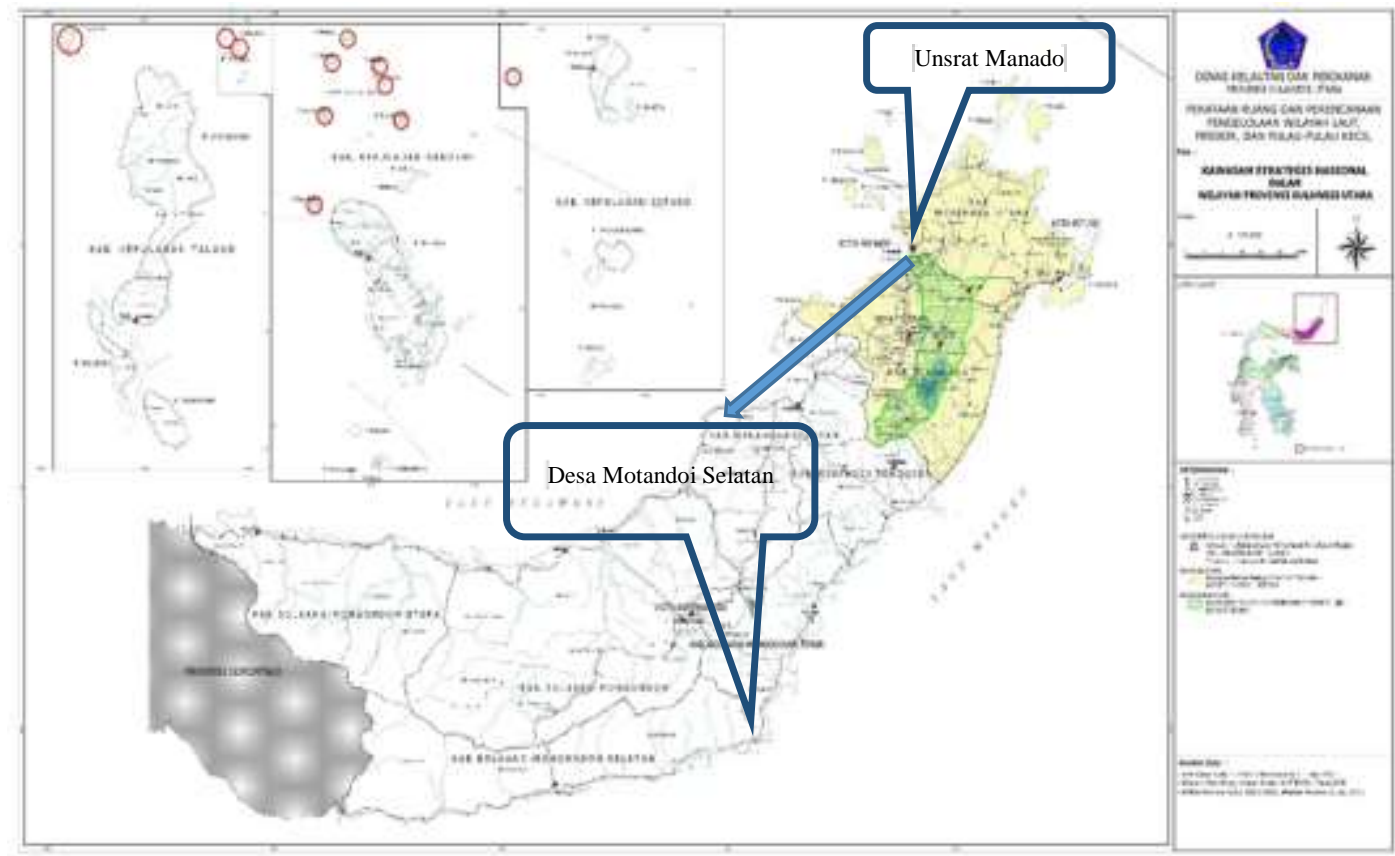

Gambar 1. Peta lokasi mitra sasaran, Desa Motandoi Selatan, Kecamatan Pinolosian Timur, Kabupaten Bolaang Mongondow Selatan, Provinsi Sulawesi Utara.

\section{Aspek sumber daya manusia}

Jumlah penduduk di Desa Motandoi Selatan adalah 1.025 orang dari $345 \mathrm{KK}$. Terdapat hanya 1 sekolah TK dan 1 Sekolah Dasar (SD). Pekerjaan masyarakat meliputi: Nelayan $75 \%$, Tani $15 \%$, PNS $5 \%$ dan lainnya $5 \%$. Khusus untuk 2 (dua) kelompok mitra, masingmasing berjumlah 10 orang setiap kelompok, semuanya laki-laki, terdapat 6 orang tamat dari SMP dan 12 lainnya lulusan SD atau tidak tamat. Semua anggota kelompok adalah kepala keluarga yang menggantungkan hidupnya dari hasil budidaya ikan, nelayan ataupun berkebun (Anonimous, 2010).

\section{Aspek produksi}

Perekonomian masyarakat di Desa Motandoi Selatan pada umunya ditopang oleh dua mata pencarian utama, yaitu hasilhasil laut dan pertanian. Sektor pertanian secara umum meliputi kopra, cengkih, pisang dan umbi-umbian. Hasil laut dari kegiatan perikanan meliputi ikan-ikan 
pelagis seperti ikan Deho, Cakalang dan ikan Terbang serta ikan-ikan karang lainnya seperti Kuwe, Beronang, Goropa, dan lainlain. Ada 6 pengusaha budidaya laut dalam karamba jaring apung (KJA) di desa ini, dua diantaranya adalah mitra dalam kegiatan Program Kemitraan Masyarakat (PKM) ini. Sebagian besar hasil usaha budidaya ikan laut ini dijual ke pasar Kota Kotamobagu yang berjarak $\pm 30 \mathrm{~km}$ dari tempat domisili mitra. Konsumen yang membeli sebagian besar adalah masyarakat yang berdomisi di Kota Kotamobagu (Anonimous, 2010).

Ilustrasi kondisi usaha budidaya laut sebelum melakukan kegiatan PKM di Desa Motandoi Selatan ini adalah dalam 1 tahun, mereka merencanakan 2 kali musim penebaran dengan 2 kali pemanenan. Untuk 1 kali pemanenan, biaya 2 unit KJA (8 lubang kurungan/unit KJA dengan ukuran $3 \times 3 \mathrm{~m}^{2} /$ kurungan) dengan peralatan operasionalnya berharga Rp. 50.000.000,-Biaya tenaga kerja termasuk penyusutan sejumlah Rp. 25.000.000,- per 1 siklus panen (sebagai biaya pengeluaran). Biaya penebaran ikan kerapu sebanyak 5000 ekor (ukuran $10 \mathrm{~cm} /$ ekor) dalam 2 unit KJA ditambah dengan biaya pakan rucah berharga Rp. 75.000.000,- /siklus panen (sebagai biaya pengeluaran). Panen ikan diperoleh sebanyak $2.000 \mathrm{~kg}$ dengan harga Rp. 100.000.000,- (sebagai uang penerimaan). Keuntungan mitra adalah total penerimaan Rp. 100.000.000,dikurangi total pengeluaran Rp. 100.000.000,- = Rp. 0.

Sasaran program ini adalah untuk meningkatkan nilai pertumbuhan ikan dengan waktu pemeliharaan yang lebih pendek dan pemberian pakan yang tepat disesuaikan dengan kebutuhan ikan, serta meningkatkan pendapat pembudidaya ikan atau kelompok mitra.

\section{Aspek teknologi}

Budidaya ikan laut di Desa Motandoi Selatan masih bersifat konvensional dan berpotensi selalu akan mengalami kerugian, karena sistim dan teknologi budidayanya masih relatif sederhana dengan pemanfaatan ikan rucah/pellet yang boros dan memakan biaya yang sangat besar. Bagaimanapun, jika teknologi budidaya ikan laut dapat dipelihara secara sistim polikultur dengan pemanfaatan pakan ikan rucah/pellet yang efisien (mengikuti metode ilmiah yg telah teruji), maka dapat menekan biaya pengeluaran yang relatif besar, sehingga keuntungan bagi mitra dapat lebih ditingkatkan dan sejahtera.

\section{Permasalahan Mitra}

Dalam merumuskan masalah, tim duduk bersama dengan mitra berdiskusi untuk menentukan skala prioritas masalah yang perlu mendapat solusi dengan kegiatan ini. Berdasarkan analisis situasi yang dikemukakan di atas, secara garis besar permasalahan mitra dapat dikategorikan sebagai berikut (Gambar 2):

Aspek produksi: Produksi ikan dengan mutu teknologi budidaya ikan laut yang rendah akan menghasilkan produksi ikan budidaya laut dengan pertumbuhan yang lambat dengan waktu yang lebih panjang dan dengan pemanfaatan ikan pakan rucah yang boros, sehingga biaya pengeluaran yang besar mengakibatkan keuntungan yang tidak sesuai harapan.

Aspek teknologi: Teknik budidaya yang dilakukan oleh mitra PKM masih bersifat tradisional, belum adanya penerapan teknologi budidaya ikan laut dengan teknologi yang lebih berkualitas dan efisien, seperti teknologi polikultur dalam KJA dengan memanfaatkan jenis pakan ikan yang efektif dan efisien.

Aspek SDM: 1) Kurangnya ilmu pengetahuan dan teknologi (iptek) terapan dan informasi tentang teknologi budidaya ikan laut dalam KJA yang unggul, dan 2) Pengelolaan keuangan melalui pembukuan belum standard, sehingga proses pencatatan masuk dan keluarnya uang tidak baik. Keuangan keluarga dan usaha masih disatukan, sehingga sukar diketahui berapa 
Jurnal Pesisir dan Laut Tropis

besar keuntungan yang didapati setiap musim panen ikan.

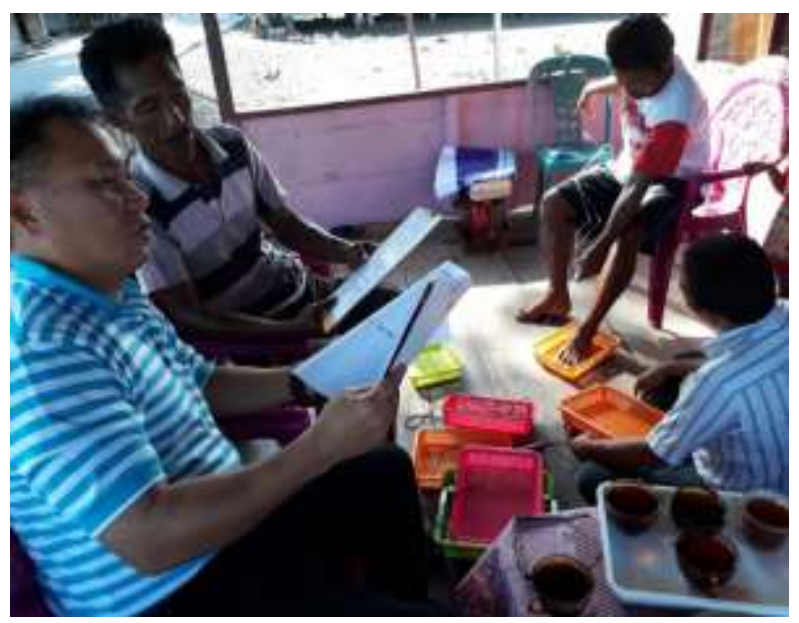

Gambar 2. Tim duduk bersama dengan mitra berdiskusi untuk menentukan skala prioritas masalah yang perlu mendapat solusi dengan kegiatan ini.

\section{METODE PELAKSANAAN}

\section{Metode}

Metode pelaksanaan pelatihan dalam kegiatan PKM ini dirancang mengacu pada pendekatan pembelajaran orang dewasa, yakni dengan memberikan teori melalui ceramah, berdiskusi, dan melakukan praktek. Dalam melaksanakan praktek, anggota kelompok mitra dibimbing oleh pelatih atau dosen, sampai pada akhirnya para anggota kelompok dapat melakukannya sendiri.

Para pelatih atau instruktur adalah para dosen yang berasal dari Fakultas Perikanan dan IImu Kelautan (FPIK) Universitas Sam Ratulangi yang memiliki pengalaman memadai dalam bidang teknologi marikultur ikan laut dalam karamba jaring apung dan manajemen usaha perikanan. Para peserta atau anggota kelompok mitra adalah masyarakat pesisir yang statusnya sebagai nelayan atau pembudidaya ikan yang menjadi mitra dan sebagai objek kegiatan.

\section{Volume 7 Nomor 3 Tahun 2019}

Proses pelaksanaan pelatihan PKM ini agar dapat berjalan secara efektif, yaitu dengan memberikan pelatihan secara langsung di lapangan menggunakan alatalat bantu pembelajaran, yakni kertas plano, spidol, gambar-gambar KJA, ikan, pakan ikan, contoh-contoh usaha-usaha perikanan yang sukses dan manajemen keuangan yang berhasil, audio visual, dan proyektor/infokus.

Berdasarkan acuan di atas maka tahapan pelatihan yang dilalui terdiri dari: 1) Pembicaraan pengantar, 2) Identifikasi masalah melalui diskusi, 3) Penyajian materi oleh penceramah atau Nara Sumber, 4) Diskusi kelompok, dan 5) Praktek. Dengan pendekatan seperti ini diharapkan seluruh peserta anggota kelompok mitra dapat berpartisipasi secara aktif, sehingga proses pelatihan dapat berlangsung secara efektif, efisien dan produktif. Para pelatih atau instruktur akan melatih para anggota kelompok mitra sampai mereka dapat mempraktekkan sendiri apa yang mereka pelajari. Proses pelatihan ini akan didampingi oleh tim pelaksana serta akan dilakukan pemantauan setiap bulannya sampai kegiatan ini selesai.

\section{Pelatihan Teknologi Polikultur Budidaya Laut Ikan Kerapu dan Beronang dalam KJA}

Sebelum karamba jaring apung (KJA) digunakan untuk kegiatan budidaya, jaring dibersihkan dari teritip serta lumutlumut yang menempel. Jaring yang telah dibersihkan diperiksa kembali jangan sampai ada jaring yang robek. Kurungan yang digunakan adalah berukuran $3 \mathrm{~m} \times 3$ $\mathrm{m} \times 3 \mathrm{~m}$, dengan ukuran mata jaring 1,5 $\mathrm{cm}$. Setiap sudut KJA dipasang pemberat masing-masing 4 kg/buah (Paruntu, 2015; Paruntu dkk., 2015; 2018).

Ikan uji dipelihara dalam 3 kurungan apung yang masing-masing kurungan diisi 250 ekor per jenis ikan. Kurungan yang pertama (K-1) akan diisi oleh campuran ikan kerapu dan ikan beronang dengan perbandingan 1:1, kurungan kedua ( $\mathrm{K}-\mathrm{II})$ akan diisi dengan ikan kerapu semata 
(Kontrol 1) dan dalam kurungan ketiga (III) akan diisi oleh ikan beronang semata (Kontrol 2). Berat badan awal ikan uji adalah sekitar 30 - 60 gram/ekor untuk ikan beronang dan 60 - 100 gram/ekor untuk ikan kerapu (Paruntu, 2015; Paruntu dkk., 2015; 2018).

Pakan ikan untuk ikan kerapu adalah ikan rucah, sedangkan pakan ikan untuk ikan beronang yaitu campuran ikan rucah dan pelet ikan mas dengan perbandingan 1:1. Waktu pemberian pakan dilakukan 2 kali sehari pada pagi hari sekitar pukul 08.00 - 10.00 dan sore hari sekitar 16.00 - 18.00. Cara pemberian pakan untuk ikan kerapu yaitu dengan cara menebarkan sedikit demi sedikit sampai ikan kenyang, sedangkan untuk ikan beronang juga diberikan sedikit demi sedikit, kemudian sisanya diletakkan dalam wadah atau sebuah baki plastik yang alasnya diberi lubang-lubang kecil dan pemberat diikatkan pada salah satu sudut bagian atas kurungan dan setelah itu nampan plastik ditenggelamkan perlahan lahan ke dalam kurungan kira-kira 0,5 meter dari dasar jaring. Pemberian jumlah pakan untuk ikan kerapu yaitu, 10-15\% dari berat tubuh total dan untuk ikan beronang yaitu $5-10 \%$ dari berat tubuh total (Paruntu, 2015; Paruntu dkk., 2015; 2018).

Pengamatan tingkat pertumbuhan dilakukan dengan mengukur panjang dan menimbang berat ikan seluruhnya setiap 2 minggu sekali. Untuk mengetahui berat ikan digunakan timbangan yang mempunyai tingkat ketelitian 5 gram. Pada saat pengukuran panjang dan berat, ikan dibius atau dianestasi dengan menggunakan minyak cengkeh dengan dosis 60 ppm selama 1 - 2 menit. Masing-masing ikan yang telah diukur dan ditimbang, dimasukkan kedalam larutan antinbiotik dengan dosis 50 ppm. Untuk menghitung pertumbuhan harian, konversi pakan, dan tingkat kematian dengan berpedoman pada formula dari Yamaguchi (1978) atau Sugama (1983).

Dalam program PKM ini dilakukan pelatihan pengukuran kualitas perairan laut di lokasi budidaya, meliputi kecepatan arus (cm/detik), oksigen terlarut (DO) (ppm), suhu $\left({ }^{\circ} \mathrm{C}\right), \mathrm{pH}$, kecerahan, salinitas (\%o) dan kedalaman perairan (m) dengan menggunakan alat ukur Horiba U-50 Series (Paruntu dkk., 2018).

\section{Pelatihan Manajemen Keuangan}

Sebelum dilakukan pelatihan, Instruktur mengidentifikasi pembukuan nelayan atau pembudidaya ikan sebagai kelompok mitra dan ditemukan bahwa mereka belum memiliki pembukuan yang baik (penggunaan uang, baik pembelian maupun penjualan tidak dicatat). Menangani masalah pembukuan yang belum memenuhi standar tersebut dilakukan dengan memberi pelatihan manajemen keuangan yang baik, sehingga semua pengeluaran dan pemasukan tercatat dengan baik. Melakukan pengelolaan keuangan yang baik diharapkan pada akhir bulan dapat diketahui berapa besar pengeluaran dan pemasukan keuangan mereka, sehingga dapat mengetahui keuntungan yang diperoleh setiap bulan. Dalam pelatihan ini ditegaskan bahwa antara modal usaha dengan belanja rumah tangga perlu dipisahkan.

Untuk merealisasikan dengan baik kegiatan PKM ini, maka disusun rencana kegiatan sebagai berikut:

1. Mempersiapkan peralatan dan bahan yang akan digunakan dalam pelatihan, sambil berkordinasi dengan Tim Pelaksana PKM.

2. Melakukan pelatihan/penyuluhan tentang teknik polikultur budidaya ikan laut dalam KJA yang unggul dan manajemen usaha perikanan yang baik.

3. Praktek di lapangan tentang teknologi polikutur budidaya ikan laut dalam KJA dan manajemen keuangan yang baik bagi kelompok mitra.

4. Monitoring dan evaluasi.

5. Pelaporan. 


\section{HASIL DAN PEMBAHASAN}

Iptek bagi Pembudidaya Ikan tentang Biologi Ikan Laut dan Peluang Polikultur dalam KJA

Melalui kegiatan PKM ini, 2 (dua) kelompok pembudidaya ikan target, yaitu Kelompok Pembudidaya Ikan "Goropa" dan Kelompok Pembudidaya Ikan "Cuma Janji" memperoleh ilmu pengetahuan dan teknologi tentang biologi ikan budidaya laut ekonomis penting, seperti ikan kerapu dan beronang dan peluang kedua jenis ikan ini untuk dipelihara bersama dalam karamba jaring apung sebagai teknologi budidaya laut unggul yang dapat meningkatkan pendapatan nelayan/pembudidaya ikan. Iptek biologi laut tentang ikan kerapu dan beronang yang dijelaskan kepada anggotaanggota kelompok pembudidaya ikan melalui pelatihan dan penyuluhan oleh para dosen/instruktur dari FPIK Unsrat, sebagai berikut, bahwa ikan kerapu (Epinephelus spp.) termasuk famili Serranidae, lebih popular dalam bahasa Inggris dikenal sebagai "Grouper". Hidupnya di daerah pantai, karang dan laut dalam sampai kedalaman 60 meter, hidupnya soliter, di alam memangsa ikan dan crustacea (Nurdalila dkk., 2015; Paruntu dkk., 2018). Penyebaran ikan kerapu meliputi daerah tropik dan subtropik (Randall dan Ben Tuvia, 1983). Di alam, ikan kerapu sering ditemui berlindung di antara terumbu karang, atau benda-benda yang tenggelam lainnya dan menyergap mangsa dari posisi persembunyiannya (Nurdalila $d k k$., 2015). Sedangkan, ikan beronang, Siganus spp. (Percomorphi, Siganidae) yang dalam bahasa Inggrisnya disebut "Rabbit fish", karena mempunyai bentuk kepala seperti kelinci dan termasuk salah satu ikan karang yang mendiami perairan tropis Indo-Pasifik (Munro, 1967). Ikan ini bersifat menggerombol, sehingga dapat dipelihara di tempat-tempat terbatas dengan padat penebaran yang tinggi (Lam, 1974 dan Merta, 1982). Disamping itupula Wardana (1976) mengatakan, bahwa jenis-jenis ikan beronang bersifat herbivora, akan tetapi juga mudah menerima jenis makanan lain yang diberikan (Jaikumar dkk., 2011).

Bertolak dari sifat-sifat kedua jenis ikan tersebut di atas, maka memberikan peluang besar ikan-ikan laut ekonomis penting ini untuk dipelihara bersama dengan teknik polikultur dalam karamba jaring apung. Penggunaan karamba jaring apung untuk budidaya ikan laut adalah salah satu, sistem yang paling produktif untuk budidaya secara intensif (Teng dan Chua, 1980; Outtara dkk., 2003).

Iptek bagi Pembudidaya Ikan tentang Teknologi Polikultur Budidaya Laut dalam KJA

IImu pengetahuan dan teknologi polikultur budidya laut yang diajarkan kepada kelompok pembudidaya ikan di pesisir pantai Desa Motandoi Selatan Kecamatan Pinolosian Timur Kabupaten Bolaang Mongondow Selatan melalui program kemitraan masyarakat (PKM) adalah suatu cara yang tepat untuk transfer iptek bagi masyarakat dalam rangka peningkatan kesejahteraan masyarakat dengan pendekatan kesejahteraan ekologi. Pelibatan masyarakat pembudidaya ikan dalam kegiatan program kemitraan masyarakat ini penting untuk menumbuhkan rasa memiliki dan rasa tanggung jawab dalam mensejahterakan keluarganya dan dapat memberikan efek kepada kelompok pembudidaya ikan atau kelaurga nelayan lainnya. Melalui kegiatan program kemitraan masyarakat ini, kedua kelompok pembudidya ikan target, yaitu Kelompok Pembudidaya Ikan "Goropa" dan Kelompok Pembudidaya Ikan "Cuma Janji" memperoleh Iptek tentang teknologi polikultur budidaya laut dalam KJA, yaitu : Ikan kerapu (Epinephelus tauvina) dan ikan beronang samadar (Siganus canaliculatus) sebagai ikan target budidaya ekonomis penting dapat diperoleh dari nelayan, pembudidaya ikan setempat atau Balai Benih Ikan yang berada di sekitar lokasi budidaya. Ukuran benih ikan kerapu dan beronang yang digunakan relatif sama, 
dengan masing-masing ukuran berkisar antara 60-100 gram dan 30-60 gram, yang terlebih dahulu diadaptasikan selama 3 minggu dalam karamba jaring apung yang telah terpasang di laut. Jenis pakan yang digunakan adalah ikan rucah segar (Stolephorus spp.) untuk ikan kerapu polikultur, selanjutnya pellet ikan mas komersial dicampur dengan ikan rucah segar (Stolephorus spp.) dengan perbandingan 1:1 untuk ikan beronang polikultur. Jumlah pemberian pakan untuk ikan kerapu sebesar 10-15 \% dari berat total tubuh per hari dan untuk ikan beronang 5-10 \% dari berat total tubuh per hari. Frekuensi pemberian pakan dilakukan 2 kali sehari, yaitu 08:00-10:00 (pagi) dan 16:00 18:00 (sore). Bagaimanapun pemberian pakan dilakukan sampai ikan-ikan budidaya tersebut tidak mau makan lagi. Wadah yang digunakan berupa KJA adalah berukuran $3 \mathrm{~m} \times 3 \mathrm{~m} \times 3 \mathrm{~m}$ dengan jumlah kurungan yang digunakan sesuai dengan kebutuhan. Setiap KJA mempunyai volume air sekitar 22,5 $\mathrm{m}^{3}$ (3 $\left.\mathrm{m} \times 3 \mathrm{~m} \times 2,5 \mathrm{~m}\right)$ diisi ikan kerapu dan beronang dengan kepadatan ideal sekitar $15-25$ ind. $/ \mathrm{m}^{3}$ atau disesuaikan dengan kebutuhan. Konstruksi karamba jaring apung (KJA) sebagai rakit terbuat dari kayu balok, kayu rep, papan dan paku, serta pelampung dari styrofoam diikat dengan tali nylon, sedangkan jaring kurungan dari polyetilin dengan ukuran mata jaring 1,5 inchi. Rakit berbentuk empat persegi panjang, yaitu 7,5 m x 7,5 m yang dibagi menjadi 4 kotak dan masingmasing kurungan berukuran $3 \mathrm{~m} \times 3 \mathrm{~m}$. Jumlah unit karamba jaring apung sesuai dengan kebutuhan dan di atasnya dibangun rumah jaga yang berukuran $2 \mathrm{~m} \times 2 \mathrm{~m}$ terbuat dari bahan kayu balok, papan, kayu rep, paku, atap seng dan cat. Karamba jaring apung dilengkapi dengan tempat makanan ikan beronang, yaitu sebuah baki plastik yang berukuran $40 \mathrm{~cm} \times 40 \mathrm{~cm}$ dengan dibuat beberapa lubang-lubang kecil didasar baki untuk sirkulasi air agar mudah tenggelam, kemudian digantung 50 $\mathrm{cm}$ dari dasar kurungan. Parameter kualitas air yang standard bagi budidaya laut adalah mengacu pada Kepmen LH No
51 Tahun 2004 (Anonimous, 2004), yaitu kecerahan: > $5 \mathrm{~m}$, suhu: $28-30{ }^{\circ} \mathrm{C}$, $\mathrm{pH}$ : 78,5, Salinitas 33-34 ppt, Oksigen terlarut: $>5$, kedalaman: $>7 \mathrm{~m}$, dan kecepatan arus: $15-30 \mathrm{~cm} /$ detik.

\section{Manajemen Keuangan Usaha}

Ilmu pengetahuan dan manajemen ekonomi usaha perikanan dan pembukuan yang baik diajarkan kepada kelompok pembudidaya ikan di pesisir pantai Desa Motandoi Selatan Kecamatan Pinolosian Timur Kabupaten Bolaang Mongondow Selatan melalui program kemitraan masyarakat (PKM), yang adalah suatu cara yang tepat untuk transfer iptek terapan bagi masyarakat dalam rangka peningkatan kesejahteraan masyarakat. Program PKM ini telah memberikan efek positif kepada Kelompok Mitra untuk memperoleh ketrampilan dalam pengelolaan keuangan melalui pembukuan yang baik, sehingga uang masuk dan uang keluar tercatat dengan jelas, yang akan berdampak pada efisiensi usaha perikanan dan kesejahteraan mereka. Tumiwa (2015) menyatakan bahwa ekonomi yang terorganisir adalah salah satu syarat dalam mencapai kedamaian pikiran semua anggota keluarga. Untuk itu dalam pengelolaan keuangan dibutuhkan upaya, terutama bagi ibu rumah tangga sebagai pengelola keuangan keluarga harus selalu bijaksana dalam memenuhi atau mengatur kebutuhan keluarganya. Manajemen keuangan keluarga sangat dibutuhkan untuk dikelola dengan baik, karena: 1) Uang sifatnya terbatas untuk memenuhi kebutuhan manusia, 2) Daya ingat manusia sangat terbatas (Middlecamp dan Kean, 1985), jika tidak dicatat maka uang yang dikeluarkan akan tidak diingat lagi, 3) Kebutuhan hidup manusia sangat beragam, dan dibutuhkan skala prioritas, 4) Uang sebagai bahan diskusi dan sarana komunikasi di antara anggota keluarga, 5) Pemborosan uang dapat dicegah.

$$
\text { Manulang (1982) menyatakan }
$$

bahwa pengelolaan keuangan keluarga terbagi menjadi tiga langkah, yaitu: 1) 
Mencatat semua penghasilan yang diperoleh keluarga untuk mengetahui total pendapatan keluarga per bulan , 2) Membuat daftar pengeluaran rutin sebagai pengeluaran kebutuhan pokok per bulan, seperti beras, minyak, teh, gula, sabun, pasta gigi, listrik, air, telepon, uang sekolah anak, kompor gas, pembantu, dan lain-lain, kemudian semuanya itu dijumlahkan, 3) Daftar pengeluaran tidak rutin dibuat berdasarkan skala kebutuhan prioritas. Selanjutnya total pendapatan yang kita miliki dikurangi dengan seluruh pengeluaran rutin dan tidak rutin. Apabila pengeluaran yang kita rencanakan melebihi dari pendapatan yang kita miliki, maka sudah sepatutnya diseleksi lagi biaya mana yang bisa ditunda penggunaannya. Apabila ketiga langkah tersebut di atas telah dilakukan, maka evaluasi perlu dilakukan sebelum rencana dilaksanakan. Maksud dari evaluasi dilakukan, yaitu untuk memeriksa: a) Apakah ada atau tidak ada kesalahan dalam penjumlahan, b) Apakah ada atau tidak ada kebutuhan rutin yang terlewatkan, c) Jika ada kebutuhan tidak penting, kita bisa menggantikannya dengan kebutuhan lain yang lebih penting, d) Apakah ada sebagian kebutuhan yang dapat dihemat, sehingga sisanya dapat digunakan sebagai uang pencegahan untuk kebutuhan yang tidak terduga, seperti: membiayai anggota keluarga yang sakit, mengunjungi seseorang yang meninggal, melayani jika ada tamu yang berkunjung secara tiba-tiba ke rumah, dan sebagainya, e) Penghasilan tambahan yang mungkin dapat diperoleh. Setelah kegiatan evaluasi telah selesai dilakukan, maka kita harus menulis kembali perencanaan keuangan dengan rapi dan meletakkannya di tempat yang dapat dilihat setiap hari di rumah kita.

\section{KESIMPULAN DAN SARAN}

Kelompok mitra, yaitu Kelompok "Goropa" dan Kelompok "Cuma Janji" yang mewakili masyarakat Desa Motandoi Selatan memperoleh pengetahuan dan ketrampilan tentang metode dan teknik polikultur budidaya ikan laut dalam KJA, jenis dan cara pemberian pakan ikan yang efektif dan efisien. Kelompok mitra, yaitu Kelompok "Goropa" dan Kelompok "Cuma Janji" yang mewakili masyarakat Desa Motandoi Selatan memperoleh model pembukuan kelompok nelayan yang standard dan baik, yang merupakan solusi terhadap sistem pencatatan yang kurang baik selama ini yang terjadi pada kelompok nelayan, sehingga pemasukan dan pengeluaran tercatat dengan baik. Kelompok mitra, yaitu Kelompok "Goropa" dan Kelompok "Cuma Janji" disarankan untuk membangun kerjasama dengan lembaga/dinas terkait setempat, yaitu antara lain Dinas Kelautan dan Perikanan Kabupaten Bolaang Mongondow Selatan untuk keberlanjutan kegiatan usaha budidaya laut yang sedang dilakukan dalam rangka kesejahteraan pembudidaya ikan atau nelayan.

\section{DAFTAR PUSTAKA}

Anonimous, 2004. Keputusan Menteri Negara Lingkungan Hidup No. 51 Tahun 2004 tentang Baku Mutu Air Laut. Menteri Negara Lingkungan Hidup. 5 hal.

Anonimous, 2010. Rencana pembangunan jangka menengah (RPJM) Desa. Pemerintah Desa Motandoi Selatan. Kecamatan Pinolosian Timur. Kabupaten Bolaang Mongondow Selatan. Molibagu. 49 hal.

Jaikumar, M., L. Kanagu, C. Stella, B. Gunalan, 2011. Culturing a rabbitfish (Siganus canalicullatus) in cages: A study from Palk Bay, South East Coast of India. International Journal of Water Resources and Environmental Engineering 3(11):251-257.

Lam, T. J. 1974. Siganid. Their biology and mariculture potential. Aquaculture (3). Pp. 324-354.

Manulang M., 1982. Pengantar ekonomi perusahaan Cet: 9. BKLM Yogyakarta: Liberty. 255 hal. 
Merta, S., 1982. Studi ekologi ikan Beronang (Siganus canaliculatus) di perairan Teluk Banten Pantai Utara Jawa barat. Thesis IPB. Bogor. 130 hal.

Middlecamp, C. and E. Kean, 1985. Panduan belajar Kimia Dasar. PT. Gramedia Jakarta. 190 hal.

Munro, S. R. Ian, 1967. The fisheries of New Guine. Dept. Agri. Stock and Fish. Port Moresby. $631 \mathrm{p}$.

Nurdalila, A. A., H. Bunawan, S. V. Kumar, K.F. Rodrigues, S. N. Baharum, 2015. Homogeneous nature of Malaysian marine fish Epinephelus fuscoguttatus (Perciformes; Serranidae): Evidence based on molecular markers, morphology and fourier transform infrared analysis. International Journal of Molecular Sciences 16:14884-14900.

Paruntu, C.P., 2015. Budidaya ikan Kerapu (Epinephelus tauvina Forsskal, 1775) dan Ikan Beronang (Siganus canaliculatus Park, 1797) dalam Karamba Jaring Apung dengan Sistim Polikultur. Jurnal Budidaya Perairan, Vo. 3, No. 1: 1-10.

Paruntu, C. P., P. Tumewu, dan S. D. Anis, 2015. Pengembangan kawasan agrotechno berbasis tanpa limbah. Conference Proceedings: Bappenas International Conference on Best Development Practices and Policies: 38-46.

Paruntu, C. P., S. Darwisito, A. P. Rumengan, J. H. Sinjal, 2018. The effects of monoculture or polyculture of tiger grouper (Epinephelus fuscoguttatus) and rabbittish (Siganus canaliculatus) on the growth performance of tiger grouper in floating net cage. AACL Bioflux 11(3):635-644.

Outtara, N. I., G. G. Teugels, V. N'Douba, J. C. Philippart, 2003. Aquaculture potential of the black-chinned tilapia, Sarotherodon melanotheron (Cichlidae). Comparative study of the effect of stocking density on growth performance of landlockes and natural populations under cage culture conditions in Lake Ayame (Côte d'Ivoire). Aquaculture Research 34:1223-1229.

Randal, J. E, A. Ben-Tuvia, 1983. A review of the grouper (Pisces: Serrenidae; Epinephelus) of the Red Sea, with description of a new species of Chephalophalis. Bull. of Marine Science 32 (2). Pp. 373-426.

Sugama, K., 1983. Pertumbuhan ikan Kakap merah, Lutjanus altifrontalis dalam kurung-kurung apung. Laporan Penelitian Perikanan Laut. (29). Jakarta. Hal. 61-68.

Teng, S. K. and T. E. Chua, 1980. Economic production of estuary grouper. Epinephelus salmoides Maxwell, reared in floating net-cages aquaculture, 20. Pp. 187-228.

Tumiwa, J. R., $2015 . \quad$ Analisa pengaruh pendidikan terhadap pendapatan rumah tangga melalui kewirausahaan sebuah analisa jalur. Jurnal of Asean Studies on Maritime Issues Vol. 1 No 1. 23 hal.

Wardana, I., $1976 . \quad$ Percobaan pemeliharaan ikan beronang/keakea (Siganus virgatus) dan kerapu (Epinephelus spp.) di Pulau Pari, Teluk Jakarta. Lap. Pen. Perikanan Laut. Jakarta. Hal.1-6.

Yamaguchi M., 1978 Practical and culture method of Read Sea-Bream. Koseikoku. Japan, 301 p. [In Japanese]. 